\title{
Medicinal Properties of Njavara Rice (Oryza Sativa
}

L.) cv.

\author{
Reshmi.R ${ }^{1 *}$, Nandini P.V ${ }^{2}$
}

\begin{abstract}
A study was conducted to find out the therapeutic value of medicinal rice (Oryza sativa L.) $c v$. Njavara. Njavara rice for the study was procured from Rice Research Station, Moncompu.

For assessing the efficacy of Njavara on the blood sugar levels, a feeding trial for 3 months was conducted among five subjects who were diabetic and willing to participate but not on medication. Blood sugar levels were monitored during 0, 45 and $90^{\text {th }}$ day of supplementation.

The results revealed that for all subjects' blood sugar levels decreased after supplementation study.

Diphenyl picryl hydrazyl (DPPH) radical scavenging activity, hydroxyl radical scavenging activity, superoxide anion radical scavenging activity and Vitamin E level were also ascertained.

The findings revealed that after the supplementation of Njavara, the DPPH scavenging activity, hydroxyl radical activity, superoxide anion-radical scavenging activity and vitamin E level of the blood samples of all the five subjects under study have increased.
\end{abstract}

Keywords- Njavara, Rice, Antioxidants, supplementation.

\section{INTRODUCTION}

Rice has been used as a medicine by traditional healers from time immemorial. Kerala has an immense wealth of medicinal rice cultivars. Among the various medicinal rices, Njavara is a unique grain plant in the Oryza genus indigenous to Kerala, widely used in the Ayurvedic system of medicine, especially in Panchakarma treatment. Documents show that it has been under cultivation in Kerala for about 2500 years since the time of Susruta.

Njavara rice, with a distinct gene pool and medicinal properties, can be exploited as nutraceutical rice (Sulochana and Bakiyalakshmi, 2011).

Studies related to therapeutic value of Njavara rice are rather limited. So the present study is an attempt to investigate the above said parameters.
II. MATERIALS \& METHODS

Njavara rice was collected from Rice Research Station of Kerala Agriculture University, Moncompu

In order to assess the therapeutic value of Njavara rice, supplementation study was carried in which Njavara rice in grits form was prepared in the laboratory and was given to selected human volunteers with diabetes mellitus.

\section{Conduct of case studies}

For the conduct of the case studies, five human subjects who were diabetic but not on medication in the age group of 40-50 years and who were willing to participate were purposively selected through personal interview. After the selection process, preliminary information regarding their socio-economic profile, health status, dietary and life style pattern and nutritional status were collected through a suitably structured questionnaire.

1) Socio-economic profile

In order to elicit information on socio-economic profile of the respondents details regarding age of the subjects, family income, type and size of the family, religion, educational status, money spent on food and health care etc. were collected using the questionnaire.

Using the pre-tested questionnaire, the subjects' food habits and dietary pattern were collected. In life style pattern, the subjects' personal habits like consumption of alcohol, smoking, stress and strain in the daily life, habit of doing exercise etc. were also collected.

\section{2) Nutritional status}

Nutritional status of the selected respondents was assessed through anthropometry. Anthropometric measurements relevant to the study include height, weight and BMI and Waist-Hip ratio.

3) Conduct of feeding trail 
The selected subjects were supplied the Njavara grits for a period of three months based on their individual calorie requirement and disease condition.

4) Assessment of the efficacy of the Njavara grits

The feeding trail was conducted for a period of 3 months to assess the efficacy of the Njavara grits on the blood glucose levels of the subjects. Blood glucose level of the subjects were taken initially (before the feeding trial), intermittently (after 45 years) and finally (after the feeding trial).

5) Antioxidant properties
a.
Diphenyl Picryl
scavenging activity
Hydrazyl
(DPPH) radical

Free radical scavenging activity of sample to characterize antioxidant activity was estimated as suggested by Blois (1958). Different amount of the blood samples were taken (with the help of a lab technician) and DPPH (0.1 mM dissolved in methanol) was mixed together and the reaction mixture was left in dark room for 20 minutes. The absorbance was measured at $517 \mathrm{~nm}$ against the blank prepared by mixing DPPH and methanol. The antioxidant activity was expressed in terms of per cent inhibition of DPPH free radicals using the following equation:

$$
\text { DPPHradicalscavengingactivity }(\%)=\frac{\mathrm{Abs}_{\mathrm{control}}-\mathrm{Abs}_{\mathrm{sample}}}{\mathrm{Abs} \mathrm{control}} \times 100
$$

Where, $\mathrm{Abs}_{\mathrm{control}}=$ absorbance of DPPH solution (blank) and Abs sample $=$ absorbance of sample.

b. Hydroxyl radical scavenging activity

In order to assess the hydroxyl free radical scavenging activity of the methanolic extracts of the rice samples, the deoxyribose method was used, as described by Halliwell et al. (1987), with some slight modifications. The reaction mixture contained phosphate buffer $(20 \mathrm{mM}, \mathrm{pH} 7.4), 60$ $\mathrm{mM}$ deoxyribose, $10 \mathrm{mM}$ Hydrogen peroxide, $1 \mathrm{mM}$ ferric chloride, $1.04 \mathrm{mM}$ EDTA, different amount of blood samples and the final $2 \mathrm{mM}$ ascorbic acid. The reaction mixtures were incubated for $1 \mathrm{hr}$. at $37^{\circ} \mathrm{C}$, after which 17 $\mathrm{mM}$ trichloro acetic acid (TCA) was added. The mixture was then boiled for 15 minutes, ice cooled and measured for absorbance at $532 \mathrm{~nm}$. Distilled water in lieu of extract was utilized as blank and the sample solution without added deoxyribose was used as a sample blank.

c. Superoxide anion radical scavenging activity Superoxide anion scavenging activity was measured based on the method described by Robak and Gryglewski (2001). Superoxide radicals were generated in a PMS-NADH system via the oxidation of NADH and then assayed by the reduction of nitro blue tetrazolium (NBT). The superoxide radicals were generated in reaction mixture containing sodium phosphate buffer (100 mM, pH 7.4) containing $150 \mu \mathrm{M}$ NBT, $468 \mu \mathrm{M}$ NADH solution in sodium phosphate buffer and different concentrations of blood samples. To this $60 \mu \mathrm{M}$ phenozine metho sulphite (PMS) solution was added. The reaction mixture was incubated for 5 minutes at $25^{\circ} \mathrm{C}$ and the absorbance was measured at 560 nm. d) Vitamin E

Chemiluminescence method was used for the analysis of Vitamin $\mathrm{E}$ in blood samples.

\section{RESULTS \& DISCUSSION}

Five subjects having diabetes in the age group of 40-50 years and not on medication were selected for the case study (Subject A-E). Among the five subjects, two were male (A and B) and three were females (Subject C to E). All the subjects were Hindu and were from nuclear family (Table 1).

Table 1 shows that the monthly income of the subjects ranged from 30,000 to $2,00,000$. Their educational qualification ranged from plus two to PG and above, with occupation business (subject A), Govt. employee (B and C), subject $\mathrm{D}$ was a housewife whereas subject $\mathrm{E}$ was a bank employee.

Duration of the diseases revealed that subject A, C and D were having diabetes for the past 2 years, whereas subject $B$ too was having diabetes for the last nine months and Subject E for the past 3 years. Except subject B and C, all others were not having any diabetic history.

The two male subjects were found to have no exercise habit and both of them were non-vegetarians, whereas female subjects were found to have the habit of doing exercise and all of them were vegetarians.

The anthropometric data of the respondents (Table 2) revealed that subject $\mathrm{A}$ and $\mathrm{E}$ were coming under Obese grade I category, with a waist-hip ratio of 1.05 and 0.99 respectively. Whereas the other three subjects i.e. subject B, $\mathrm{C}$ and $\mathrm{D}$ were of normal category, with a waist hip ratio of $0.96,0.89$ and 0.94 respectively. 
Price et al. (2006) is of the opinion that waist hip ratio (WHR) has been found to be a more efficient predictor of mortality than BMI.).

The National Institute of Diabetes, Digestive and Kidney Diseases (NIDDK) stated that women with waist-hip ratios of more than 0.8 , and men with more than 1.0 , are at increased health risk because of their fat distribution (Marlowe et al., 2005). The author also stated that a WHR of 0.7 for women and 0.9 for men has been shown to correlate strongly with general health. Women within the 0.7 range have optimal levels of estrogen and are less susceptible to major diseases such as diabetes, cardiovascular disorders and ovarian cancers. Men with WHRs below 0.9, similarly, have been shown to be healthier.

\section{Efficacy of Njavara on the blood sugar levels}

The subjects were given Njavara grits for a period of three months based on their requirement.

Table 3 shows that all the subjects have shown a decrease in the blood sugar level. The initial blood sugar levels of subject A,B,C, D and E were $193 \mathrm{mg} / \mathrm{dl}, 140 \mathrm{mg} / \mathrm{dl}, 140$ $\mathrm{mg} / \mathrm{dl}, 150 \mathrm{mg} / \mathrm{dl}$ and $250 \mathrm{mg} / \mathrm{dl}$ and their final blood sugar level was $173 \mathrm{mg} / \mathrm{dl}, 90 \mathrm{mg} / \mathrm{dl}, 110 \mathrm{mg} / \mathrm{dl}, 109 \mathrm{mg} / \mathrm{dl}$ and $160 \mathrm{mg} / \mathrm{dl}$ respectively.

The present investigation revealed that Njavara has glucose lowering effect. The exact factor for this effect is not known but there can be a number of factors like amino acids, soluble fibre, antioxidants, phenolic compound, minerals and B-complex vitamins.

\section{Antioxidant properties}

\section{a) DPPH radical scavenging activity}

Free radical scavenging is one of the known mechanisms by which antioxidants inhibit lipid peroxidation. The results of the DPPH scavenging activity in the blood samples of the subjects revealed that after supplementation of Njavara rava, their DPPH radical activity has increased on a dose dependent manner (Figure. 1-5).

In a study done by Chrzczanowicz et al. (2008) mean values of DPPH radical scavenging activity obtained in human serum (healthy subjects) were $11.2+/-3.3$ per cent. b) Hydroxyl radical scavenging activity

Hydroxyl and superoxide radicals are the two most representative free radicals. In cellular oxidation reactions, superoxide radical is normally formed first, and its effects can be magnified because it produces other kinds of cell damaging free radicals and oxidizing agents. However, the damaging action of the hydroxyl radical is the strongest among free radicals.

In the present investigation, the results revealed that after the supplementation of Njavara grits for three months the hydroxyl scavenging activity of the serum has increased when compared to the activity level before supplementation (Figure. 6-10).

c) Superoxide anion-radical scavenging activity Superoxide radical is known to be very harmful to cellular components as a precursor of more reactive species.

The superoxide scavenging activity of serum of subjects under study of the present investigation has shown an increase after the feeding trial, which is also on a dose dependent manner (Figure. 11-15).

d) Vitamin E

Vitamin $\mathrm{E}$ is a fat-soluble antioxidant that stops the production of ROS formed when fat undergoes oxidation. Scientists are investigating whether, by limiting free-radical production and possibly through other mechanisms, vitamin $\mathrm{E}$ might help prevent or delay the chronic diseases associated with free radicals (Dietrich et al., 2006).

In the present investigation, the vitamin $\mathrm{E}$ status of the subjects under study revealed that there is an increase in their vitamin $\mathrm{E}$ levels after the supplementation of Njavara rava from 23.00 to $25.62 \mu \mathrm{g} / \mathrm{ml}, 9.80$ to 13.35 $\mu \mathrm{g} / \mathrm{ml}, 19.96$ to $22.65 \mu \mathrm{g} / \mathrm{ml}, 24.00$ to $25.47 \mu \mathrm{g} / \mathrm{ml}$ and 16.00 to $18.90 \mu \mathrm{g} / \mathrm{ml}$ respectively for subjects A, B, C, $\mathrm{D}$ and $\mathrm{E}$.

\section{CONCLUSION}

Medicinal plants are a source of antioxidants and bioactive compounds present in them are responsible for the prevention of oxidative stress that leads to many degenerative diseases and conditions (Smitha et al., 2012).

The results of the study revealed that Njavara was having glucose lowering effect and good antioxidant properties. 
Table.1: Socio economic profile of the selected respondents

\begin{tabular}{|l|c|c|c|c|c|}
\hline \multirow{2}{*}{ Particulars } & \multicolumn{5}{|c|}{ Subjects } \\
\cline { 2 - 6 } & A & B & C & D & E \\
\hline Age (yrs.) & 47 & 43 & 48 & 49 & F \\
Gender & $\mathrm{M}$ & $\mathrm{M}$ & $\mathrm{F}$ & $\mathrm{F}$ \\
Family income & $30,000-40,000$ & $40,000-45,000$ & $>2,00,000$ & $50,000-60,000$ & $70,000-80,000$ \\
(Rs.) & Degree & Degree & PG & Plus two & PG \\
Educational status & & & and above & & \\
\hline
\end{tabular}

Table.2: Anthropometric parameters of the selected subjects

\begin{tabular}{|l|l|l|l|l|l|}
\hline \multicolumn{1}{|c|}{$\begin{array}{c}\text { Body } \\
\text { measurements }\end{array}$} & \multicolumn{1}{c|}{ Subject A } & \multicolumn{1}{c|}{ Subject B } & \multicolumn{1}{c|}{ Subject C } & \multicolumn{1}{c|}{ Subject D } & \multicolumn{1}{c|}{ Subject E } \\
\hline Ht. (cms) & 165 & 170 & 157 & 150 & 162 \\
Wt. (Kg) & 73 & 65 & 60 & 53 & 74 \\
BMI & 26.81 & 22.49 & 24.34 & 23.56 & 28.20 \\
\hline
\end{tabular}

Table.3: Fasting Blood sugar levels of subjects before and after supplementation

\begin{tabular}{|l|c|c|c|c|c|}
\hline \multirow{2}{*}{$\begin{array}{l}\text { Monitoring } \\
\text { intervals }\end{array}$} & \multicolumn{5}{|c|}{ Blood sugar levels (mg/dl) } \\
\cline { 2 - 6 } & Subject A & Subject B & Subject C & Subject D & Subject E \\
\hline Initial (Fasting) & 193 & 140 & 140 & 150 & 250 \\
Final & 173 & 90 & 110 & 109 & 160 \\
\hline
\end{tabular}

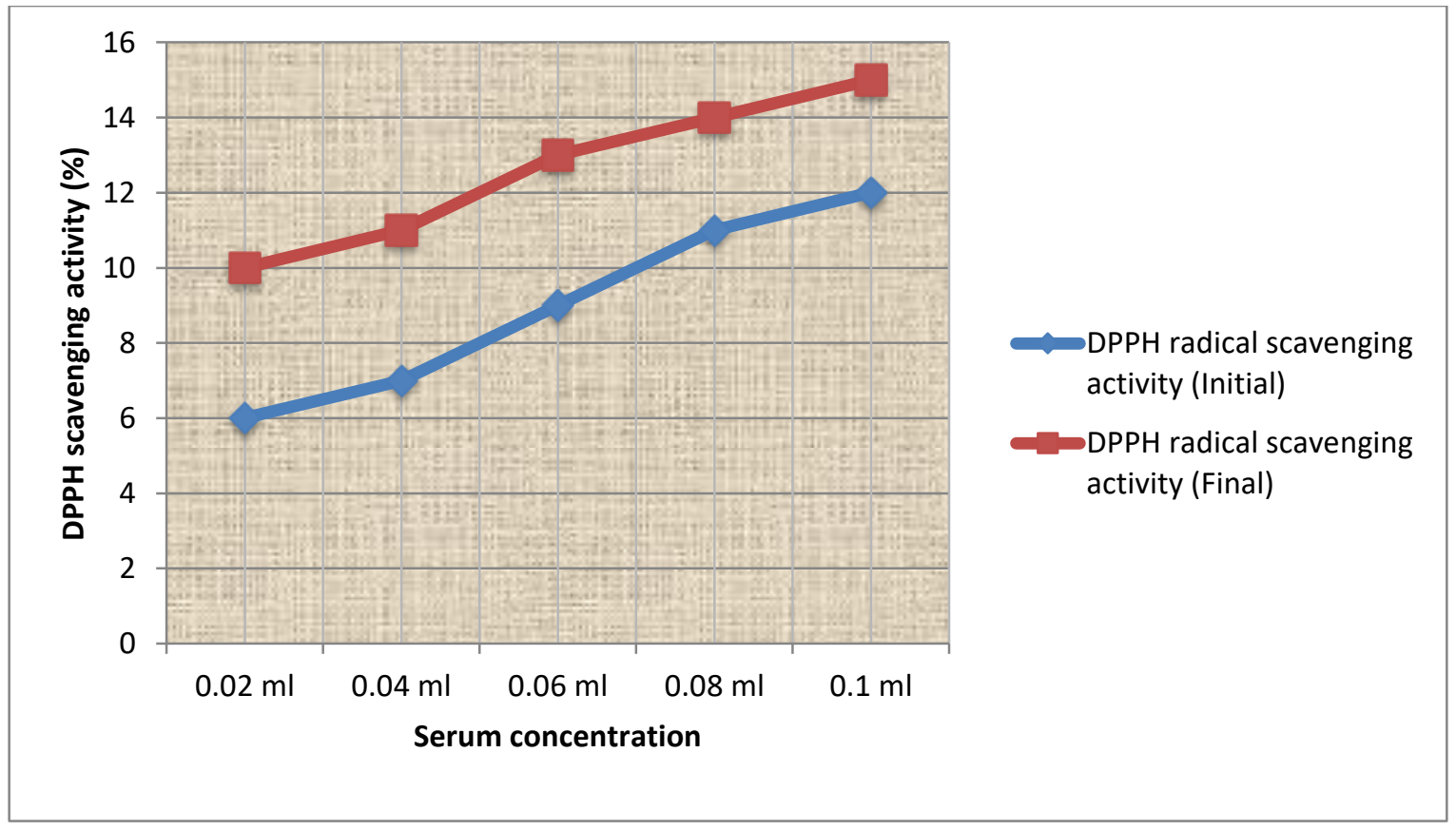

Fig.1: DPPH radical scavenging activity of subject A (before and after supplementation) 


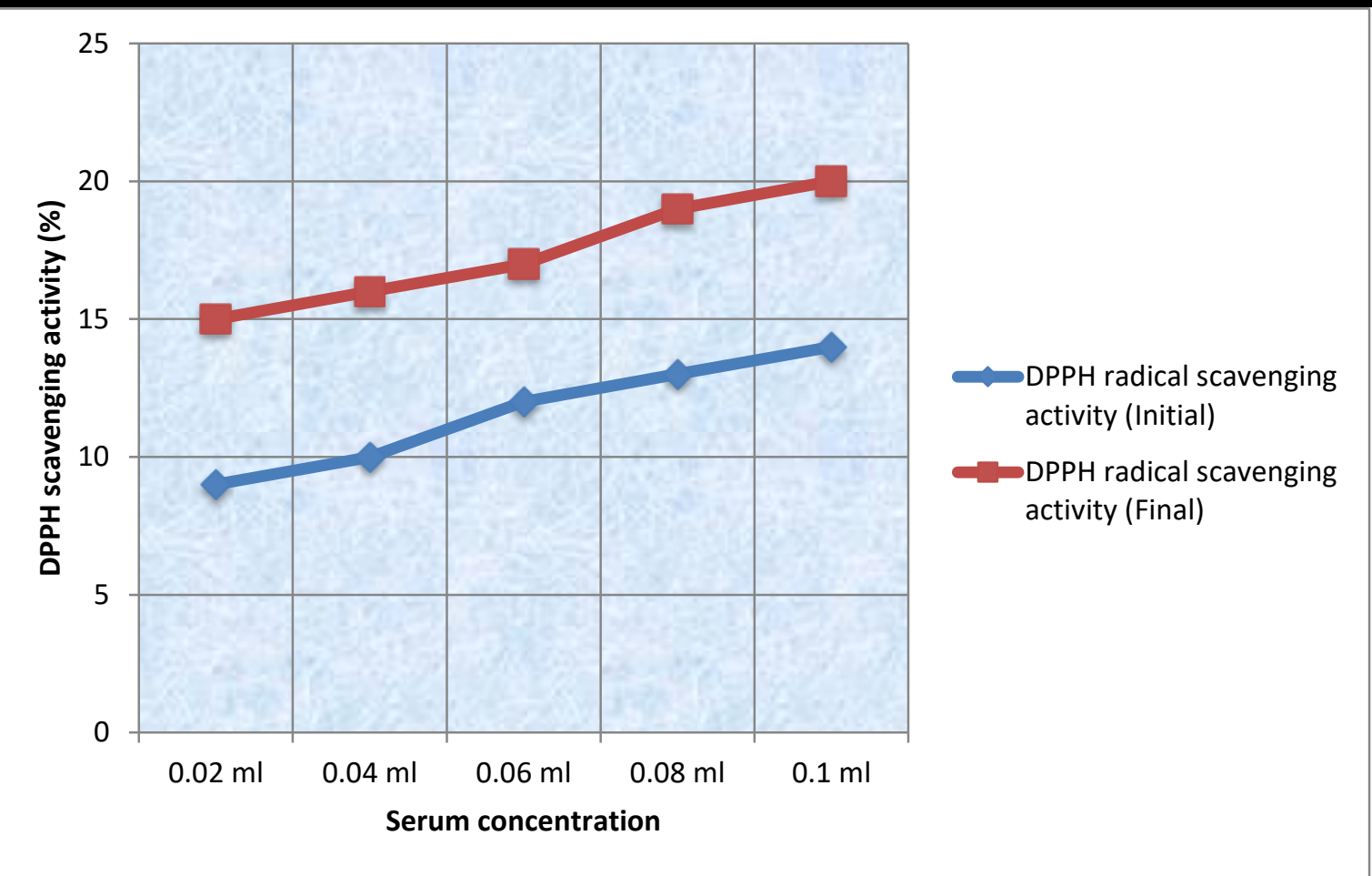

Fig.2: DPPH radical scavenging activity of subject B (before and after supplementation)

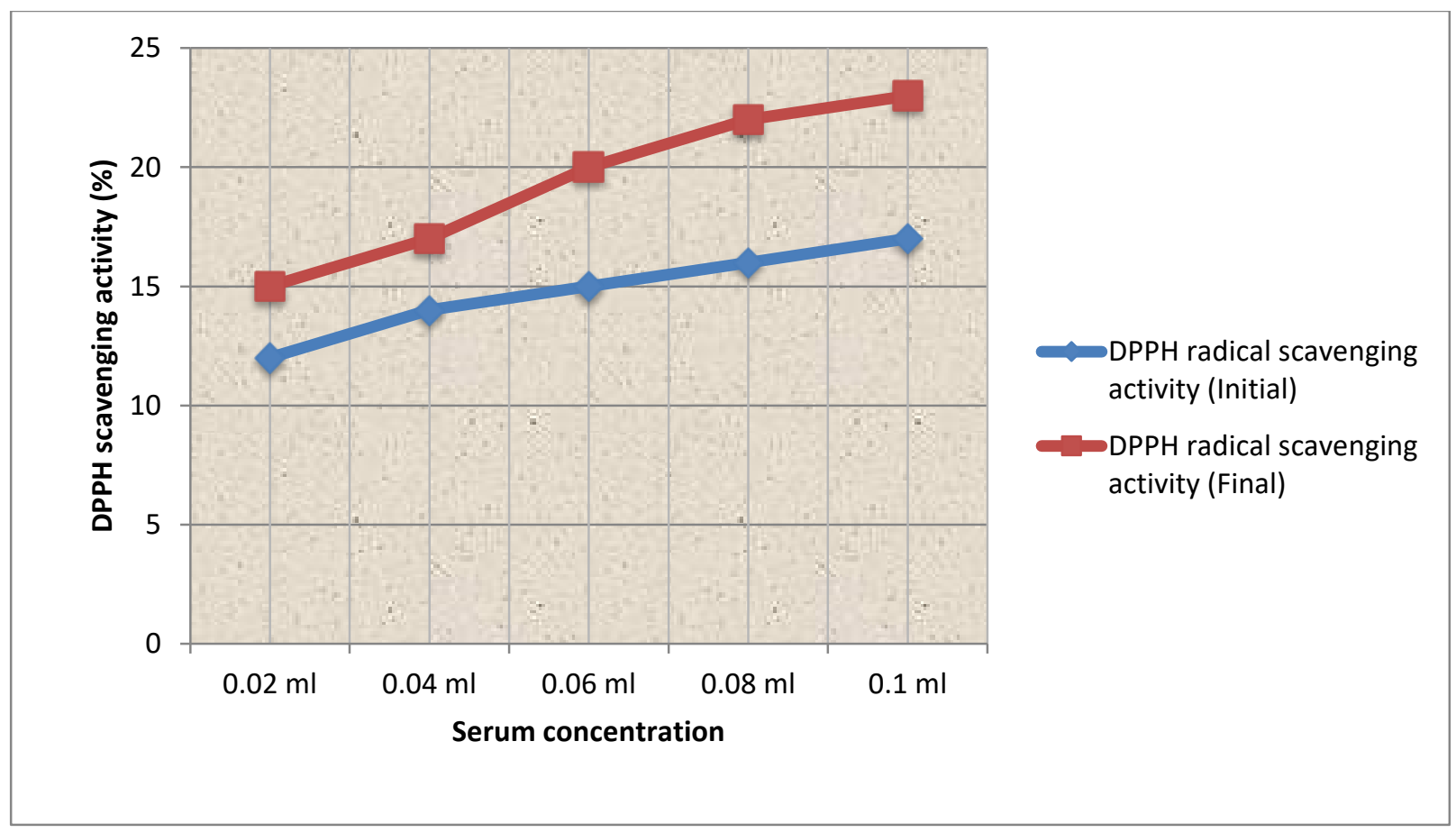

Fig.3: DPPH radical scavenging activity of subject $C$ (before and after supplementation) 


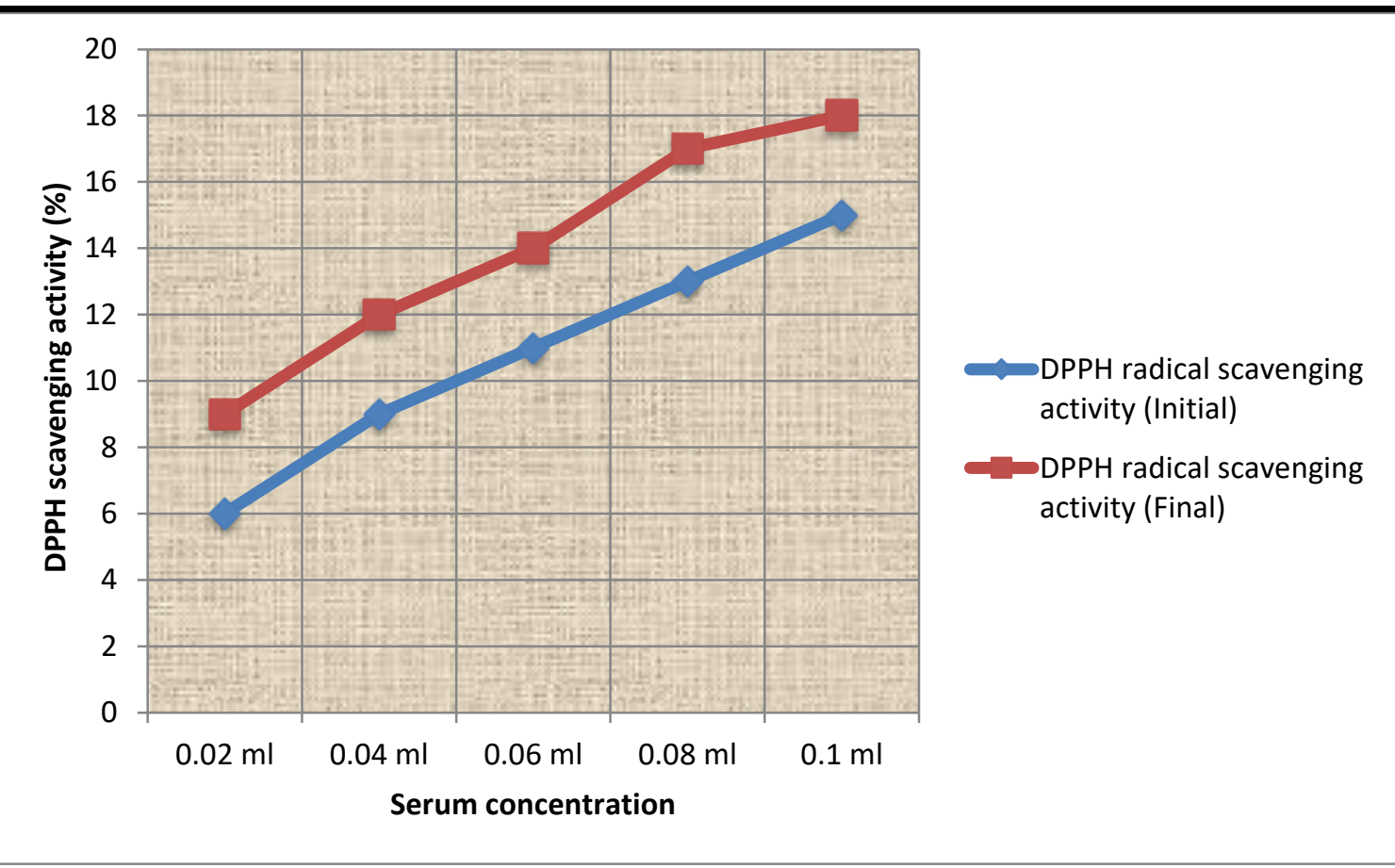

Fig.4: DPPH radical scavenging activity of subject D (before and after supplementation)

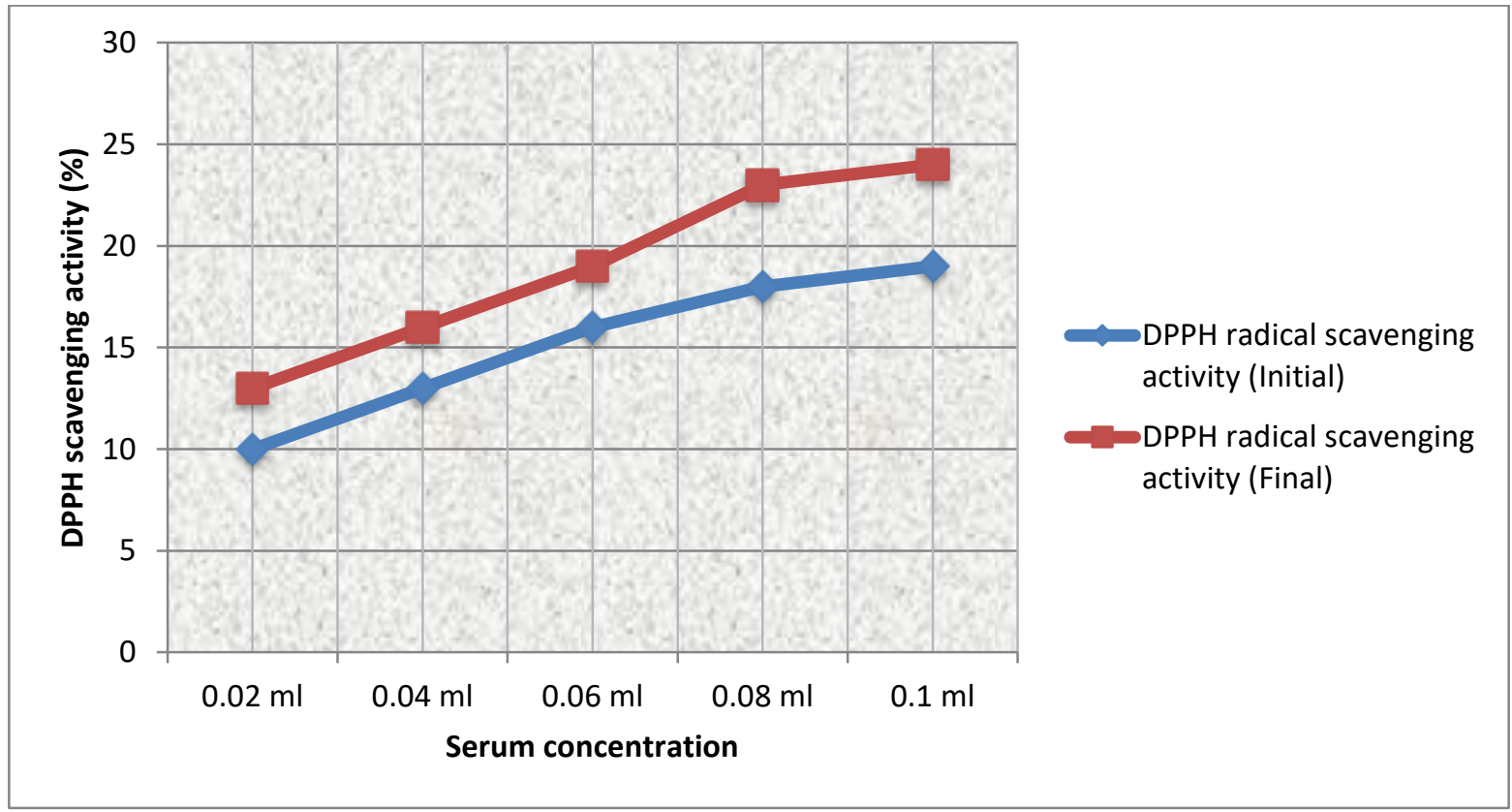

Fig.5: DPPH radical scavenging activity of subject $E$ (before and after supplementation) 


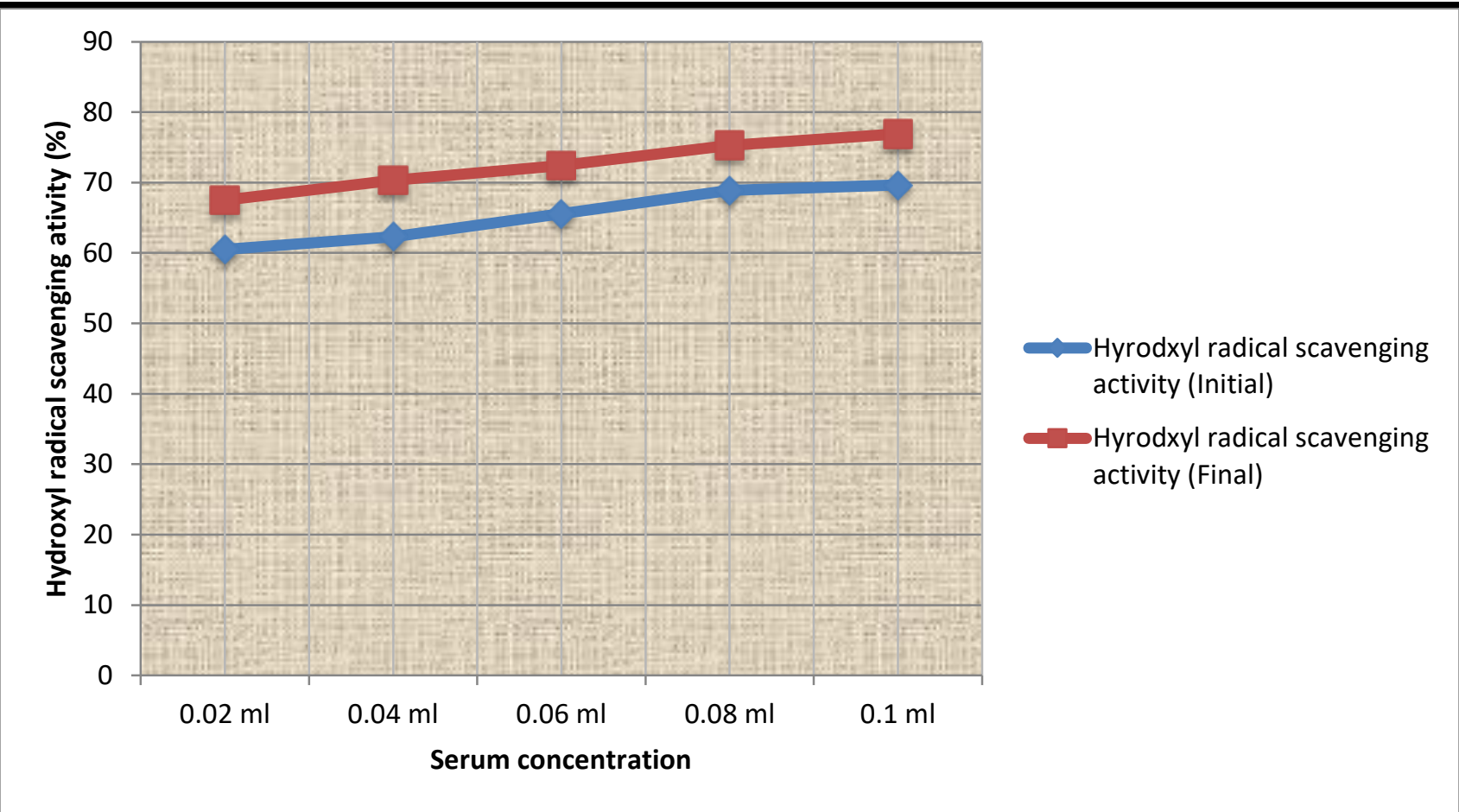

Fig.6: Hydroxyl radical scavenging activity of subject A (before and after supplementation)

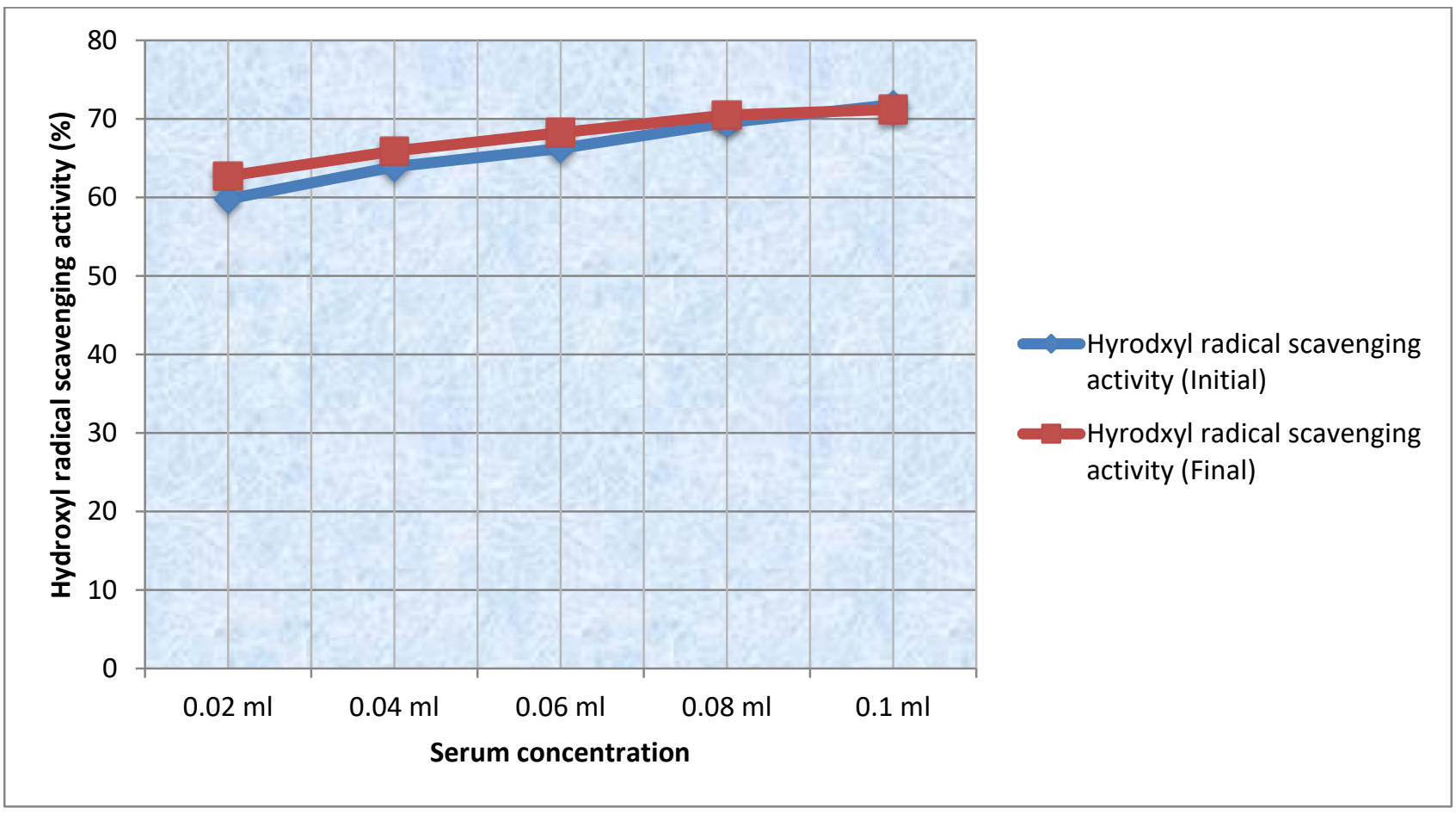

Fig.7: Hydroxyl radical scavenging activity of subject B (before and after supplementation) 


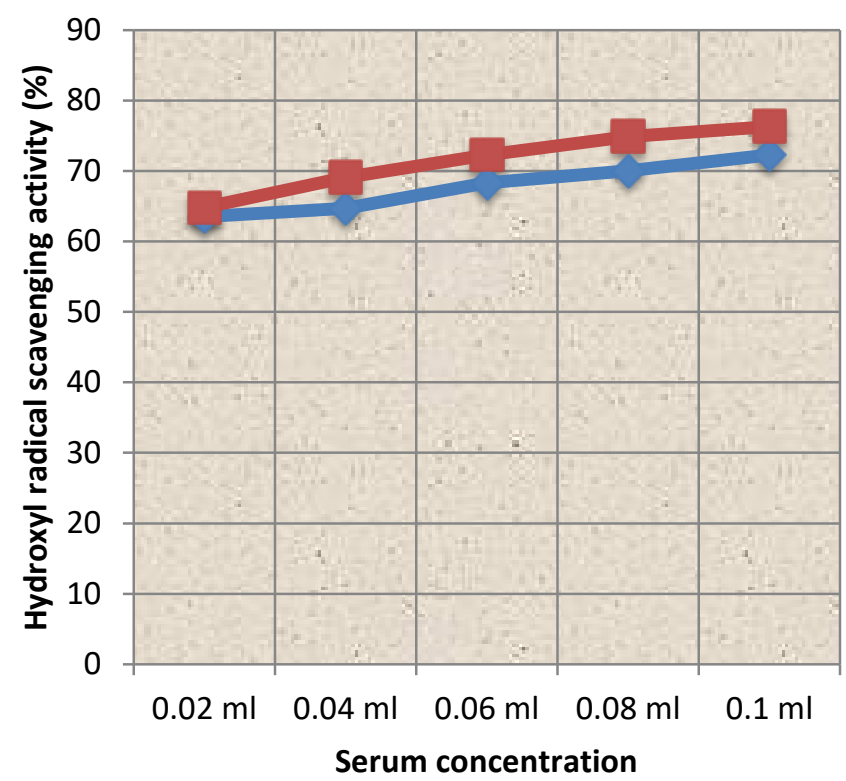

Hyrodxyl radical scavenging activity (Initial)

$-H y r o d x y l$ radical scavenging activity (Final)

Fig.8: Hydroxyl radical scavenging activity of subject $C$ (before and after supplementation)

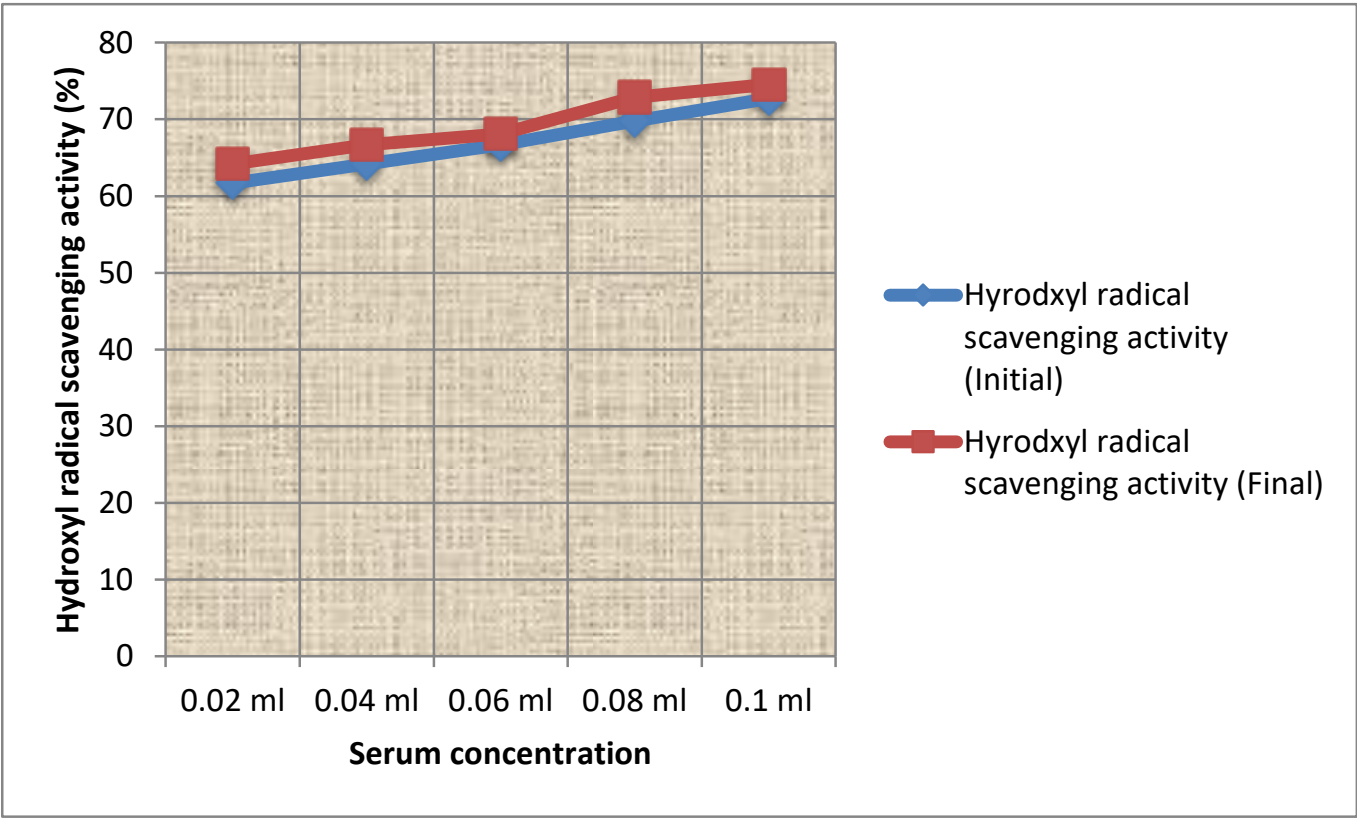

Fig. 9: Hydroxyl radical scavenging activity of subject D (before and after supplementation) 


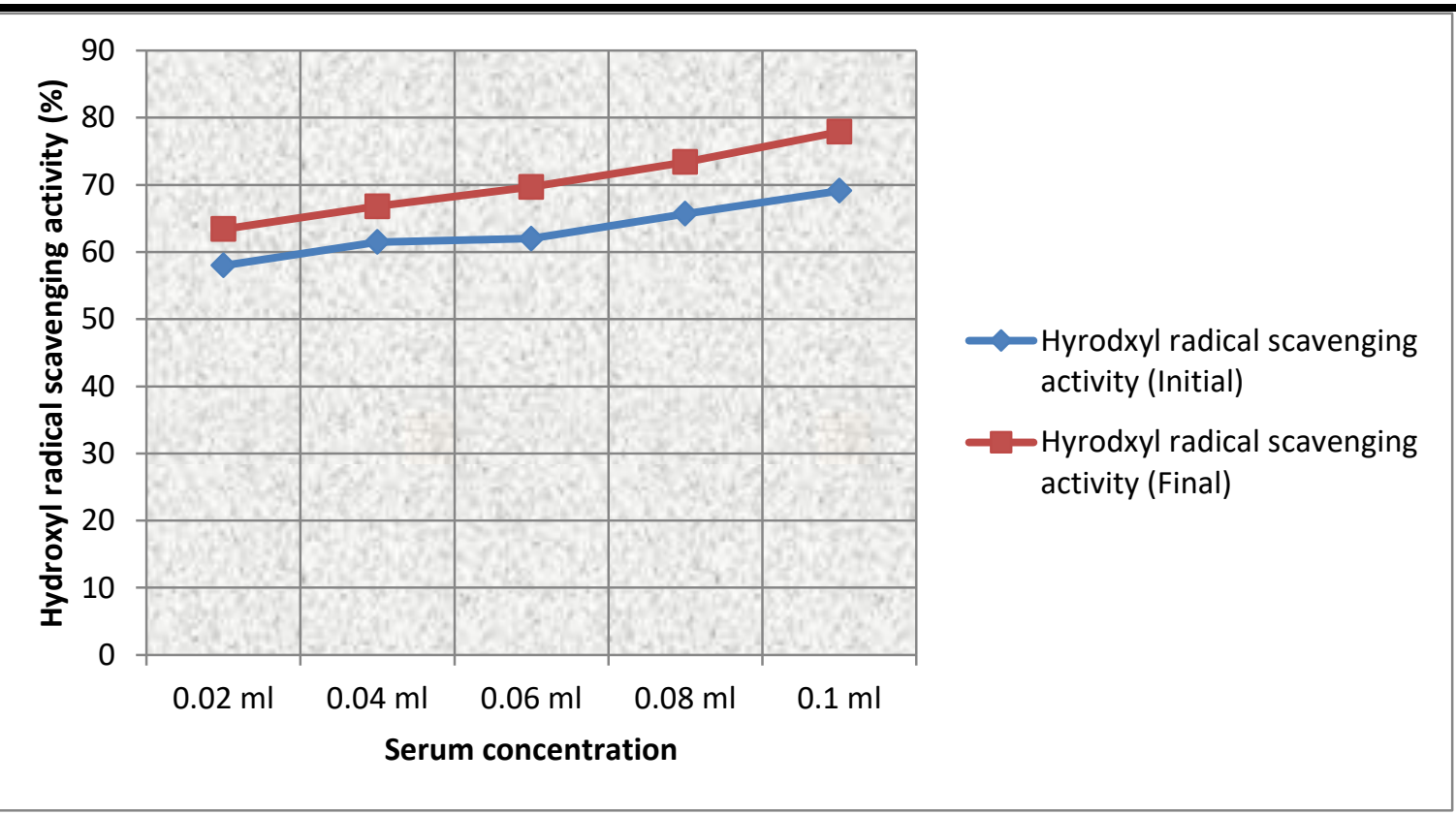

Fig.10: Hydroxyl radical scavenging activity of subject $E$ (before and after supplementation)

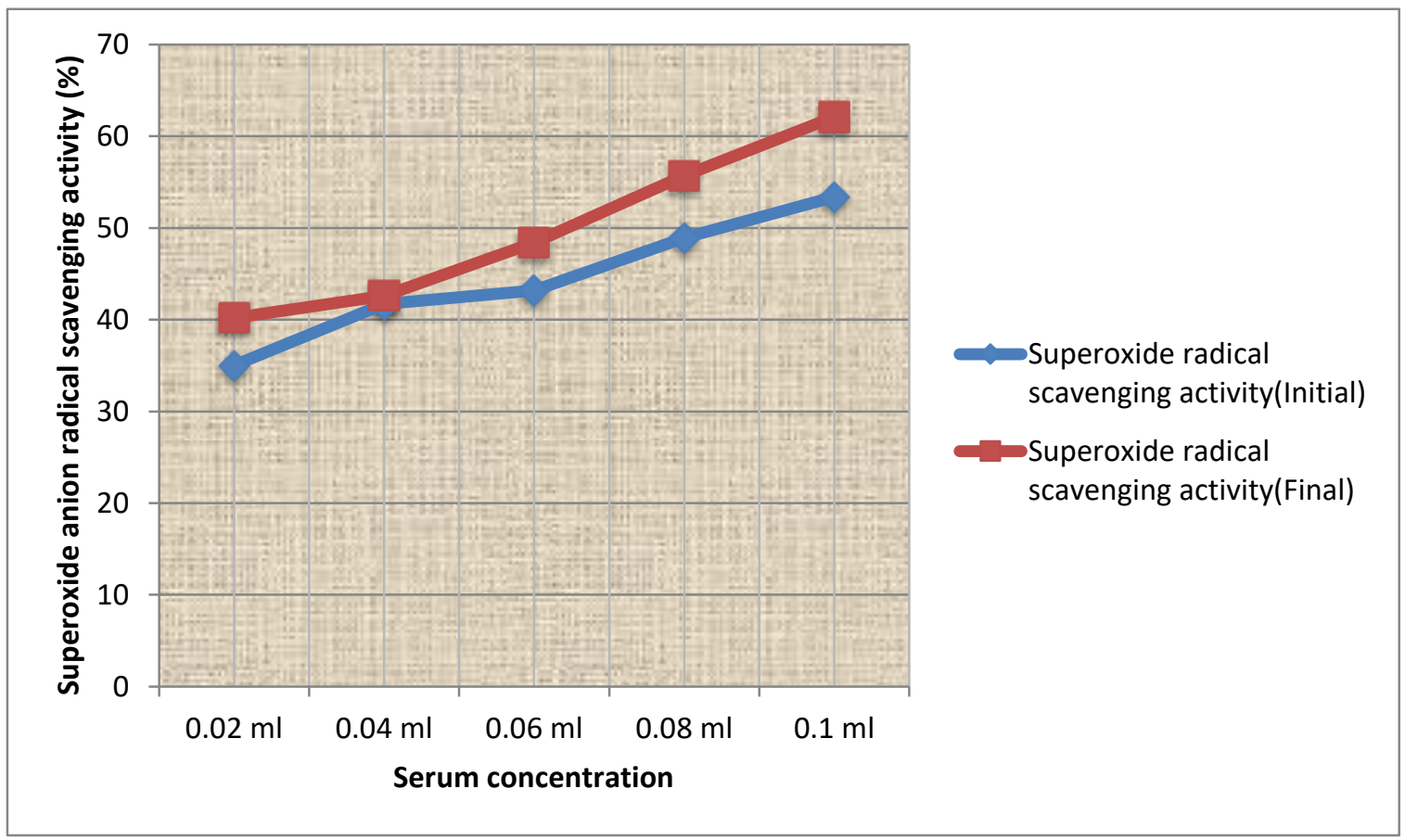

Fig.11: Superoxide anion radical scavenging activity of subject A (before and after supplementation) 


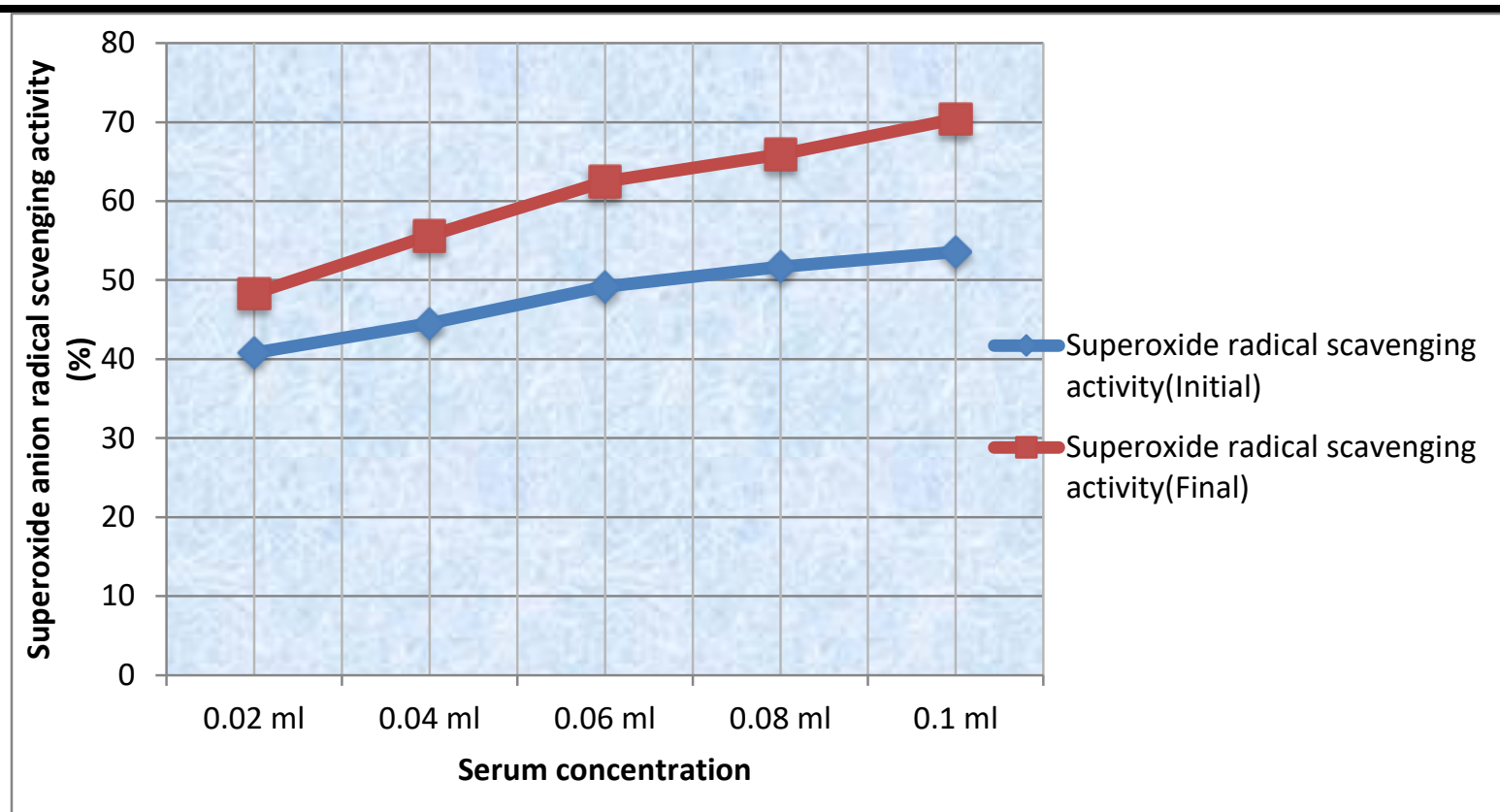

Fig. 12: Superoxide anion radical scavenging activity of subject B (before and after supplementation)

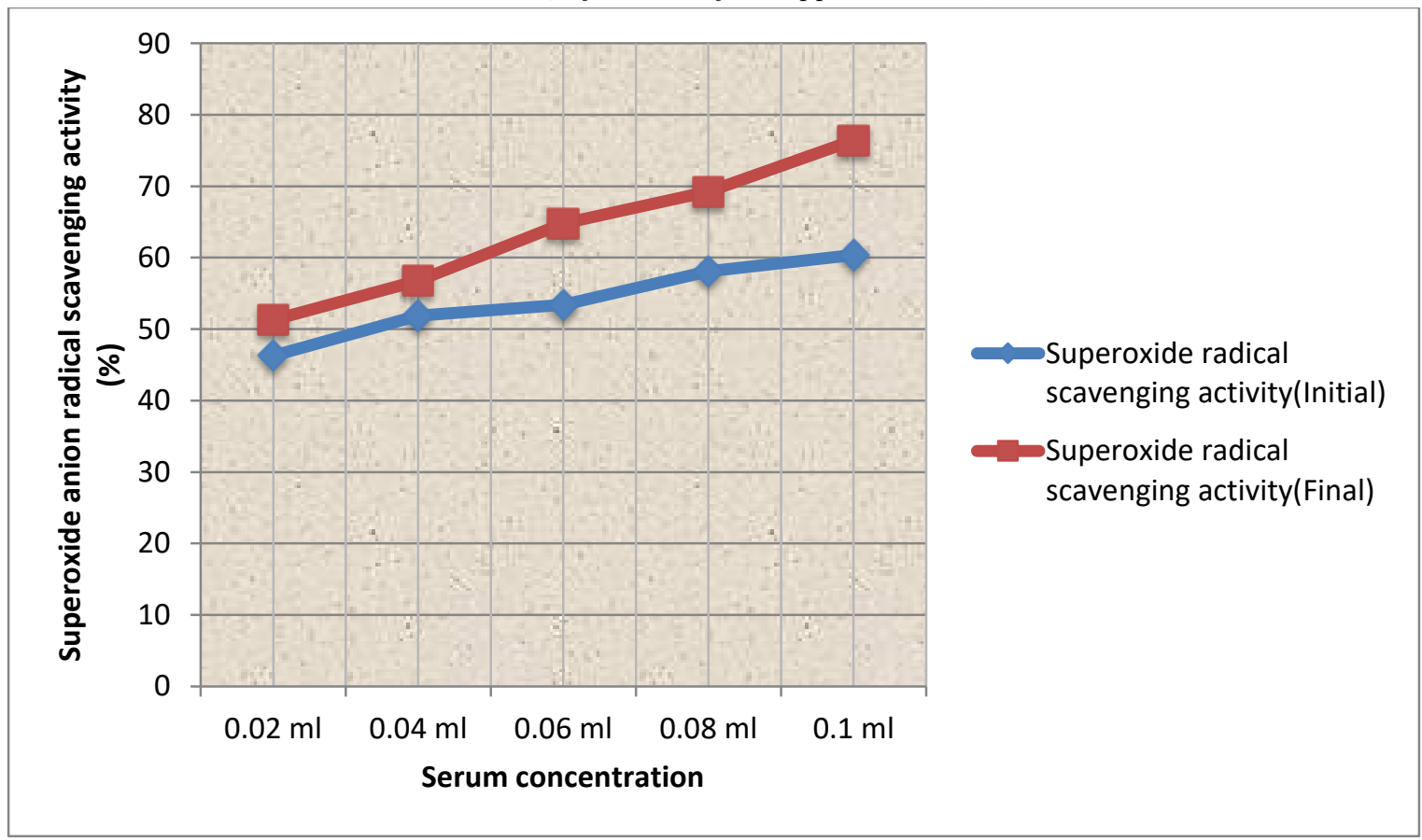

Fig.13: Superoxide anion radical scavenging activity of subject $C$ (before and after supplementation) 


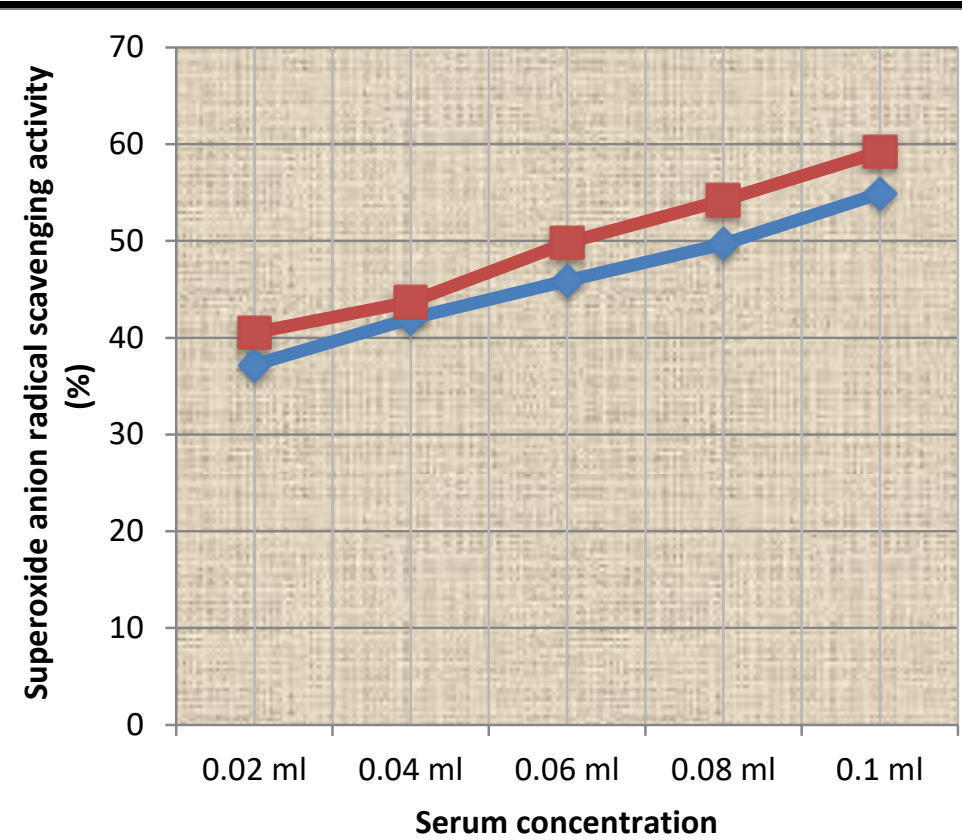

Superoxide radical scavenging activity(Initial)

- Superoxide radical scavenging activity(Final)

Fig. 14: Superoxide anion radical scavenging activity of subject $D$ (before and after supplementation)

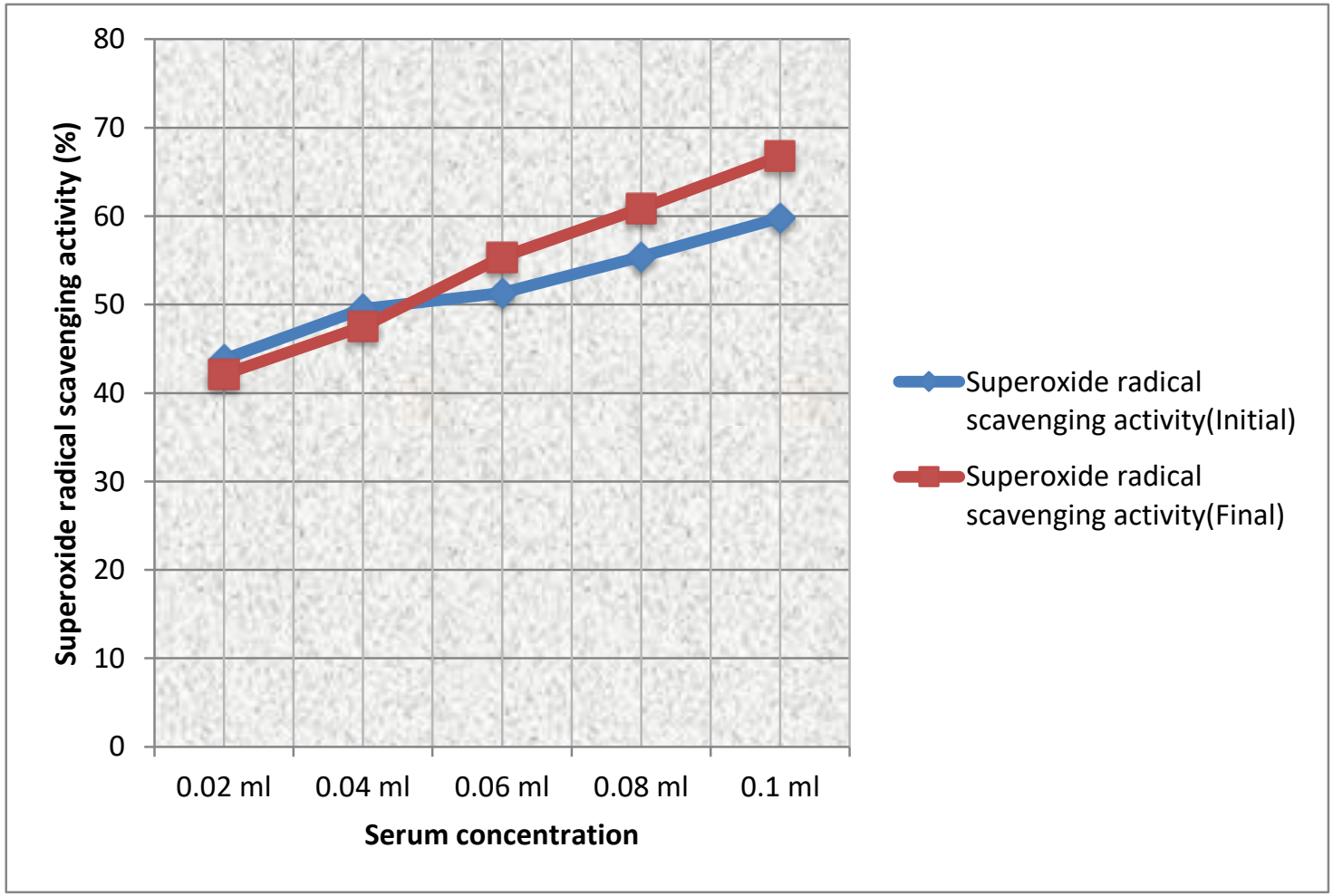

Fig. 15: Superoxide anion radical scavenging activity of subject $E$ (before and after supplementation) 


\section{REFERENCES}

[1] Blois M.S. Antioxidant determinations by the use of stable free radicals. Nature. 1958;81:1199-2000.

[2] Chrzczanowicz J, Gawron A, Zwolinska A, de GraftJohnson J, Krajewski W, Krol M., Markowski J, Kostka T Nowak, D. Simple method for determining human serum 2,2-diphenyl-1-picryl-hydrazyl (DPPH) radical scavenging activity - possible application in clinical studies on dietary antioxidants. Clin Chem Lab Med.2008; 46(3):342-349.

[3] Dietrich M, Traber, M G, Jacques, P F, Cross, C E, $\mathrm{Hu}, \mathrm{Y}$ Block, G. Does $\gamma$-tocopherol play a role in the primary prevention of heart disease and cancer? A review. Am J Coll Nutr.2006; (25):292-299.

[4] Halliwell B, Gutteridge J M C, Aruoma O I. The deoxyribose method a simple assays fro determination of rate constants for reaction of hydroxyl radicals. Anal. Biochem.1987; (165): 215-219.

[5] Marlowe F, Apicella C, Reed, D. "Men's preferences for women's profile waist-to-hip ratio in two societies". Evolution and Human Behavior.2005; 26 (6): 458-68.

[6] Price G M, Uauy R, Breeze E, Bulpitt CJ Fletcher A E. "Weight, shape, and mortality risk in older persons: elevated waist-hip ratio, not high body mass index, is associated with a greater risk of death". Am. J. Clin. Nutr. 2006; 84 (2): 449-60.

[7] Robak J, Gryglewski I RFlavonoids are scavengers of superoxide anions. Biochem. Pharmacol.2001; (37): 837-841.

[8] Smitha M, Parvathy R, Shalini V, Mohanan R, Helen A, Jayalekshmy A. Chemical indices, antioxidant activity and anti-inflammatory effect of extracts of the medicinal rice "Njavara" And Staple Varieties: A Comparative Study. J. Food. Biochem. 2012; doi: 10.1111/j.1745-4514.2011.00646.x

[9] Sulochana S, Bakiyalakshmi S V. Effect of neutraceutical dosa on antimicrobial activity. Inter. J. Envt. Sciences. 2011; (5): 727-735. 